FACTA UNIVERSITATIS

Series: Mechanical Engineering Vol. 17, Nº 3, 2019, pp. 365 - 383

https://doi.org/10.22190/FUME190605043D

Original scientific paper

\title{
OPTIMIZATION OF MULTI-PASS FACE MILLING PARAMETERS USING METAHEURISTIC ALGORITHMS
}

\author{
Sunny Diyaley ${ }^{1}$, Shankar Chakraborty ${ }^{2}$ \\ ${ }^{1}$ Department of Mechanical Engineering, Sikkim Manipal Institute of Technology, Sikkim \\ Manipal University, Majitar, Sikkim, India \\ ${ }^{2}$ Department of Production Engineering, Jadavpur University, Kolkata, India
}

\begin{abstract}
In this paper, six metaheuristic algorithms, in the form of artificial bee colony optimization, ant colony optimization, particle swarm optimization, differential evolution, firefly algorithm and teaching-learning-based optimization techniques are applied for parametric optimization of a multi-pass face milling process. Using those algorithms, the optimal values of cutting speed, feed rate and depth of cut for both roughing and finishing operations are determined for having minimum total production time and total production cost. It is observed that the teaching-learning-based optimization algorithm outperforms the others with respect to accuracy and consistency of the derived solutions as well as computational speed. Two statistical tests, i.e. paired t-test and Wilcoxson signed rank test also confirm its superiority over the remaining algorithms. Finally, these metaheuristics are employed for multi-objective optimization of the considered multi-pass milling process while concurrently minimizing both the objectives.
\end{abstract}

Key Words: Multi-pass Milling, Optimization, Metaheuristic, Objective, Parameter

\section{INTRODUCTION}

In manufacturing industries, machining is considered as one of the most important processes to remove excess amount of material from a given workpiece so as to fulfill the end requirements of the customers. In machining processes, a cutting tool having material harder than the part/component being shaped is employed for material removal by shear deformation in the form of chips. During manufacturing, the workpiece may require different machining operations, like turning, milling, drilling, reaming, grinding, etc. In the milling process, the material is removed from the workpiece by a rotating multiple tooth cutter. With the rotation of the cutter, each tooth removes a small amount of the

Received June 05, 2019 / Accepted November 10, 2019

Corresponding author: S. Chakraborty

Department of Production Engineering, Jadavpur University, Kolkata

E-mail: s_chakraborty00@yahoo.co.in 
material from the advancing workpiece during each spindle revolution. As the relative movement between the cutter and the workpiece can be in any direction, different workpiece surfaces, like flat, angular, curved or any combination of them can be machined in milling. In the face milling operation, the cutter, mounted on a spindle rotating perpendicular to the surface, provides a high material removal rate due to the cutting action of many teeth on its periphery and face. The milling operation is usually performed in a single pass or in multiple passes. The multi-pass milling is always preferable to a single pass operation for better machining economies and is utilized to shape workpieces that cannot be machined in a single pass. The multi-pass operation in the face milling often results in low power consumption, machining force, machine depreciation and chatter phenomena. The multipass milling, having complicated material removal mechanism, consists of multiple rough passes and one finish pass. Major portion of the material is removed from the workpiece during multiple rough passes. The single finish pass is mainly responsible for surface smoothening. Fig. 1 exhibits a typical multi-pass face milling operation.

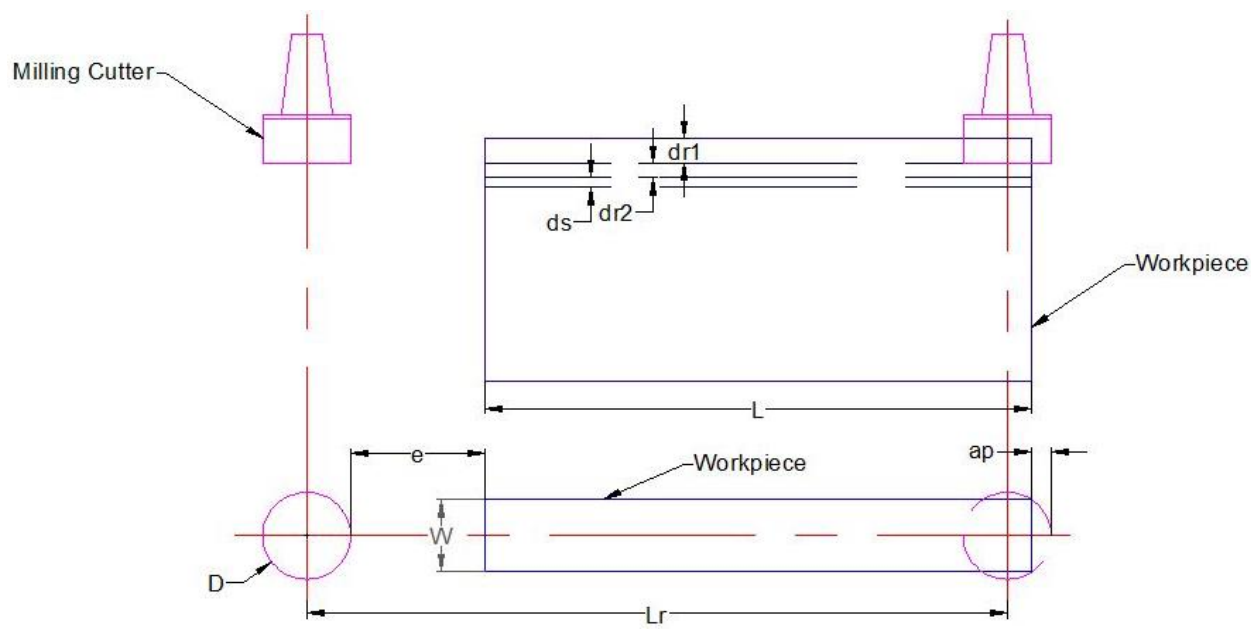

(a) Roughing

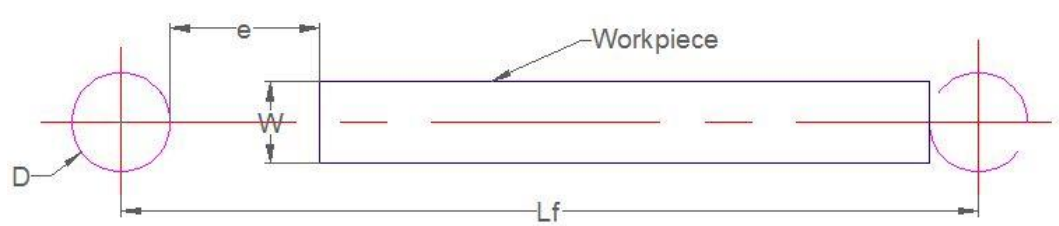

(b) Finishing

Fig. 1 Multi-pass face milling operation

In the present day manufacturing environment, multi-pass milling processes are extensively used for production of low cost high quality parts/components. Due to a high capital cost, it is always recommended to operate the multi-pass milling machines efficiently and economically. The machining performance of a multi-pass milling 
operation is often characterized by the effects of its various input parameters, like cutting speed, feed rate, depth of cut, number of passes, etc. on different process outputs (responses), i.e. material removal rate, surface roughness, tool life, power consumption, amplitude of vibration, etc. The success of a multi-pass milling operation with respect to higher product quality, increased production rate, reduced machining cost and time depends on proper selection of its various input parameters $[1,2]$. Because of the complexity of this process, the determination of the optimal combination of its parameters has become a complex and challenging task [3]. It also depends on the workpiece shape, types of the cutter and work materials, technological requirements, capability of the milling machine, etc. It has been observed that in most of the cases, milling parameters are chosen from the machining database or handbook. In some occasions, the concerned machinists also participate in identifying the most tentative settings of various milling parameters based on their knowledge and expertise. But the milling parameters selected based on these resources are extremely conservative and far from their optimal values. Various mathematical programming techniques, like dynamic programming, geometric programming, linear programming, etc. have also been applied in the past to determine the optimal settings of the machining parameters during a multi-pass face milling operation. These conventional optimization techniques usually lack robustness while solving complex optimization problems. Thus, they are now being substituted by different metaheuristics which can efficiently explore the entire search space in order to find out the near optimal or global optimal solutions with a lower computational effort and time. Therefore, these metaheuristic algorithms are popularly deployed by the researchers for deriving more robust and accurate solutions. Thus, it is always advisable to implement the corresponding mathematical formulations and determine the best parametric setting of a multi-pass face milling operation based on the applications of robust optimization tools.

In this paper, a multi-objective mathematical model for a multi-pass face milling operation is considered with the aim to simultaneously minimize the total production time and total production cost. The optimization problem is also subjected to various real time machining constraints with respect to different limiting values of cutting speed, feed rate, depth of cut, tool life, surface roughness, cutting force and machining power. It is subsequently solved using six most popular metaheuristic algorithms, i.e. artificial bee colony ( $\mathrm{ABC}$ ) optimization, ant colony optimization (ACO), particle swarm optimization (PSO), differential evolution (DE), firefly algorithm (FA) and teaching-learning-based optimization (TLBO) techniques. The optimization performance of the adopted metaheuristics is also validated with respect to accuracy and consistency of the derived solutions, and computational speed.

\section{LITERATURE SURVEY}

Conceição António et al. [4] substituted depth of cut with a sequence of depths of cut and applied a genetic search approach for parametric optimization of a multi-pass milling process. Zarei et al. [5] applied harmony search (HS) algorithm to optimize various multipass face milling parameters, i.e. number of passes, depth of cut in each pass, speed and feed in order to obtain minimum total production cost. The adopted optimization tool had high convergence speed and solution accuracy as compared to genetic algorithm (GA). Rao and Pawar [6] applied three non-traditional optimization techniques, i.e. ABC, PSO and simulated annealing (SA) for minimization of production time in a multi-pass milling 
operation. While taking into account several practical machining constraints, An et al. [7] adopted GA technique to minimize the unit production cost for a multi-pass milling operation. Yang et al. [8] presented the application of a fuzzy PSO algorithm for optimization of various machining parameters in a multi-pass face milling process. The adopted technique would outperform other optimization tools with respect to minimum production cost under multiple technological constraints. Yang et al. [9] adopted a fuzzy multi-objective PSO technique for parametric optimization of a multi-pass face milling operation. It was observed that the proposed algorithm could generate efficient Pareto optimal solutions with satisfactory convergence rate. Using GA technique, An et al. [10] solved a multi-objective model so as to minimize unit production cost and total machining time, and maximize profit rate. For a face milling operation, various real time machining constraints were also considered while developing that model. Nagarchi and Patel [11] applied HS algorithm to determine the optimal values of depth of cut, speed and feed rate in a face milling operation with an aim to improve surface roughness of machined components at the minimum total production cost. Its optimization performance was later validated with respect to GA technique. Zhai et al. [12] proposed an improved TLBO algorithm, in the form of TLBO with dynamic assignment learning strategy (DATLBO), for a multi-tool milling process in order to maximize profit rate under several machining constraints. Its optimization performance was also compared with that of other techniques. Mellal and Williams [13] applied cuckoo optimization algorithm to minimize the total production time of a face milling operation and also validated its superior optimization performance. Li et al. [14] presented the application of adaptive multi-objective PSO algorithm to maximize energy efficiency and minimize production cost in a multi-pass face milling operation. Khalilpourazari and Khalilpourazary [15] employed a robust grey wolf optimizer for parametric optimization of a multi-pass milling operation, and also compared its performance against other optimization techniques. Yang [16] proposed the combined application of chaotic operator and imperialist competitive algorithm to optimize various input parameters of a multi-pass face milling operation. The optimal values of speed, feed and depth of cut in each pass were determined for minimum total production cost. Miodragović et al. [17] endeavored to modify the basic FA technique to optimize different machining parameters in multi-pass turning and multi-pass face milling operations subject to various practical operational constraints. It was concluded that the proposed algorithm had the ability to reach the global optimal solutions for complex optimization problems.

It can be observed from the survey of the existing literature that optimization of multi-pass milling processes has already caught the attention of the past researchers, and different metaheuristic algorithms, mainly in the form of GA, SA, HS, PSO, etc. have been applied for determination of the optimal values of cutting speed, feed rate, depth of cut and number of passes for the considered multi-pass milling processes. Minimizations of total production time and of total production cost as well as maximization of profit rate have mainly been treated as the objectives. The past researchers have also endeavored to integrate the concept of the fuzzy set theory with some of the metaheuristic algorithms to solve the multi-pass milling process optimization problems. But, no research work has been conducted till date to study the comparative optimization performance of the most commonly adopted metaheuristic algorithms in this domain and to identify the best algorithm. Thus, the objective of this paper is focused on the application of six metaheuristics, i.e. ABC, ACO, PSO, DE, FA and TLBO to solve a multipass milling process optimization problem, and compare their relative performance with respect to accuracy and consistency of the derived solutions, and computational speed. 


\section{Mathematical Model for Multi-PASs Face Milling OPeration}

A multi-pass milling operation usually consists of two operations, i.e. multiple roughing passes and a single finishing pass. For roughing operation, length of tool (cutter) path $\left(L_{r}\right)$ can be expressed as [17]:

$$
L_{r}=L+a_{p}+e
$$

where $L$ is the length of the workpiece, $a_{p}$ is the approach distance and $e$ is a small distance provided to avoid the chance of any possible damage. The value of $e$ is generally considered as $2-5 \mathrm{~mm}$. For a symmetrical milling operation, the approach distance can be given by:

$$
a_{p}=\frac{D}{2}-\sqrt{\left(\frac{D}{2}\right)^{2}-\left(\frac{W}{2}\right)^{2}}
$$

where $D$ is the diameter of the tool and $W$ is the width of cut.

If a single tool is employed to perform the entire machining operation, the total production time then consists of actual machining time $\left(T_{m}\right)$, machine idling time $\left(T_{I}\right)$ and tool changing time $\left(T_{r}\right)$. Thus, total production time $\left(T_{\text {total }}\right)$ can be expressed as follows:

$$
T_{\text {total }}=T_{m}+T_{I}+T_{r}
$$

The objective function can thus be stated as:

$$
F_{1}(X)=\min \left(T_{\text {total }}\right)=\min \left(T_{m}+T_{I}+T_{r}\right)
$$

The actual machining time for a single pass milling operation can be given by:

$$
T_{m}=\frac{\pi D L}{1000 V f Z}
$$

where $D$ is the tool diameter (in $\mathrm{mm}$ ), $L$ is the length of the workpiece (in mm), $V$ is the cutting speed (in $\mathrm{m} / \mathrm{min}$ ), $f$ is the feed rate per tooth (in $\mathrm{mm} /$ tooth) and $Z$ is the number of teeth.

The actual machining time (in min) in a multi-pass milling operation consists of $n$ roughing pass time $\left(t_{m r i}\right)$ and one finishing pass time $\left(t_{m s}\right)$.

$$
T_{m}=\sum_{i=1}^{n} t_{m r i}+t_{m s}
$$

where $n$ is the number of roughing passes. The actual roughing and finishing times for single pass are denoted as below:

$$
\begin{aligned}
t_{m r i} & =\frac{\pi D L_{r}}{1000 V_{r i} f_{r i} Z} \\
t_{m s} & =\frac{\pi D L_{s}}{1000 V_{s} f_{s} Z}
\end{aligned}
$$

where $V_{r i}$ and $V_{s}$ are the cutting speed in roughing and finishing operations, respectively, and $f_{r i}$ and $f_{s}$ are the feed rate per tooth in roughing and finishing operations, respectively. 
Idling time $\left(T_{I}\right)$ consists of preparation time $\left(T_{p}\right)$ (in min/piece) and idle tool motion time $\left(T_{i}\right)$ (in min). Thus,

$$
T_{I}=T_{p}+T_{i}=T_{p}+\left(h_{1} L_{s}+h_{2}\right)+n\left(h_{1} L_{r}+h_{2}\right)
$$

where $h_{1}$ (in $\mathrm{min} / \mathrm{mm}$ ) and $h_{2}$ (in $\min$ ) are the constants related to tool travel time and tool approach or depart time, and $L_{s}$ is the tool path length for finishing pass.

As a single tool is utilized for the milling operation, it needs to be changed only after it is worn out. Thus, the tool changing time is dependent on actual machining time and tool life. Tool exchange time $\left(T_{r}\right)$ (in $\min$ ) for $n$ rough passes and one finish pass can be denoted as:

$$
T_{r}=Z\left(T_{t c} \sum_{i=1}^{n} \frac{t_{m r i}}{t_{r i}}+T_{t c} \frac{t_{m s}}{t_{s}}\right)
$$

where

$$
\begin{aligned}
t_{r i} & =\left(\frac{C_{v} K_{v} D^{q_{v}}}{V_{r i} d_{r i}^{x_{v}} f_{r i}^{y_{v}} W^{s_{v}} Z^{p_{v}}}\right)^{\frac{1}{l}} \\
t_{s} & =\left(\frac{C_{v} K_{v} D^{q_{v}}}{V_{s} d_{s}^{x_{v}} f_{s}^{y_{v}} W^{s_{v}} Z^{p_{v}}}\right)^{\frac{1}{l}}
\end{aligned}
$$

where $T_{t c}$ is the tool changing time (in min/edge) for each cutting edge, $t_{r i}$ and $t_{s}$ are the values of tool life for rough and finish passes, respectively, and $C_{v}, K_{v}, x_{v}, y_{v}, s_{v}, q_{v}, p_{v}$ and $l$ are various constants and exponents related to tool and workpiece material.

Now, by substituting Eqs. (6), (9) and (10) in Eq. (3), the corresponding objective function for minimization of the total production time can be expressed as:

$$
T=\sum_{i=1}^{n} T_{r i}+T_{s}+T_{p}
$$

where

$$
\begin{gathered}
T_{r i}=t_{m r i}\left(1+Z \frac{T_{t c}}{t_{r i}}\right)+\left(h_{1} L_{r}+h_{2}\right) \\
T_{s}=t_{m s}\left(1+Z \frac{T_{t c}}{t_{s}}\right)+\left(h_{1} L_{s}+h_{2}\right)
\end{gathered}
$$

where $T_{r i}$ is the unit time for $i^{\text {th }}$ rough pass (in min/part) and $T_{\mathrm{s}}$ is the unit time required for the finish pass (in min/part).

The second objective considered here is to minimize total production cost $\left(C_{\text {total }}\right)$ which has four components, i.e. machining cost $\left(C_{m}\right)$, machine idling cost $\left(C_{I}\right)$, tool change cost $\left(C_{r}\right)$ and tool cost $\left(C_{t}\right)$. Thus, the total production cost can be given as follows:

$$
C_{\text {total }}=C_{m}+C_{I}+C_{r}+C_{t}
$$

Hence, the second objective function can be defined as:

$$
F_{2}(X)=\min \left(C_{\text {total }}\right)=\min \left(C_{m}+C_{I}+C_{r}+C_{t}\right)
$$


Machining cost $C_{m}$ depends on actual machining time $\left(T_{m}\right)$ (in min), and unit labor and overhead cost $\left(k_{0}\right)$ (in USD/min).

$$
C_{m}=k_{0} T_{m}
$$

On the other hand, machine idling $\operatorname{cost} C_{I}$ is:

$$
C_{I}=k_{0} T_{I}
$$

Tool change cost $C_{r}$ can be given as below:

$$
C_{r}=k_{0} T_{r}
$$

Tool cost $C_{t}$ can be expressed based on the following equation:

$$
C_{t}=Z\left(k_{t} \sum_{i=1}^{n} \frac{t_{m r i}}{t_{r i}}+k_{t} \frac{t_{m s}}{t_{s}}\right)
$$

where $k_{t}$ is the cost of tool material (in USD/edge).

Now, by substituting Eqs. (18)-(21) in Eq. (16), the objective function for minimum production cost can be given as follows:

$$
C=\sum_{i=1}^{n} C_{r i}+C_{s}+k_{0} T_{p}
$$

where

$$
\begin{gathered}
C_{r i}=t_{m r i}\left(k_{0}+Z \frac{k_{0} T_{t c}}{t_{r i}}+Z \frac{k_{t}}{t_{r i}}\right)+k_{0}\left(h_{1} L_{t r}+h_{2}\right) \\
C_{s}=t_{m s}\left(k_{0}+Z \frac{k_{0} T_{t c}}{t_{s}}+Z \frac{k_{t}}{t_{s}}\right)+k_{0}\left(h_{1} L_{t s}+h_{2}\right)
\end{gathered}
$$

where $C_{r i}$ is the unit cost for $i^{\text {th }}$ rough pass (in USD/part), $C_{\mathrm{s}}$ is the unit cost for finish pass (in USD/part), and $L_{t r}$ and $L_{t s}$ are the cutting travel length for rough and finishing pass, respectively.

The objective functions for minimum production time and minimum production cost are subjected to various constraints, like (a) parameter bounds, (b) cutting force constraint, (c) machine tool power constraint, (d) surface finish constraint, (e) tool life constraint and (f) number of rough passes constraint. These constraints are stated here-in-under.

(a) Parameter bounds:

For $i^{\text {th }}$ rough pass, the range for cutting speed $V_{r i}$ is

$$
\mathrm{V}_{\min } \leq V_{r i} \leq \mathrm{V}_{\max }
$$

where $\mathrm{V}_{\min }$ and $\mathrm{V}_{\max }$ are the minimum and maximum cutting speeds, respectively. For $i^{\text {th }}$ rough pass, the range for feed rate $f_{r i}$ is

$$
f_{\min } \leq f_{r i} \leq f_{\max }
$$

where $f_{\min }$ and $f_{\max }$ are the minimum and maximum feed rate, respectively. 
For $i^{\text {th }}$ rough pass, the range for depth of cut $d_{r i}$ is

$$
d_{r \min } \leq d_{r i} \leq d_{r \max }
$$

where $d_{r \text { min }}$ and $d_{r \text { max }}$ are the minimum and maximum depth of cut, respectively. There are also three similar constraints for cutting speed, feed rate and depth of cut for the finish pass.

(b) Cutting force constraints:

$$
\begin{aligned}
& g_{1}(X)=\frac{C_{u} K_{u} W^{s_{u}} Z^{p_{u}} f_{r 1}^{y_{u}} d_{r 1}^{x_{u}}}{D^{q_{u}}}-F_{\text {max }} \leq 0 \\
& g_{2}(X)=\frac{C_{u} K_{u} W^{s_{u}} Z^{p_{u}} f_{r 2}^{y_{u}} d_{r 2}^{x_{u}}}{D^{q_{u}}}-F_{\max } \leq 0 \\
& g_{3}(X)=\frac{C_{u} K_{u} W^{s_{u}} Z^{p_{u}} f_{s}^{y_{u}} d_{s}^{x_{u}}}{D^{q_{u}}}-F_{\text {max }} \leq 0
\end{aligned}
$$

where $C_{u}, K_{u}, x_{u}, y_{u}, s_{u}, p_{u}$ and $q_{u}$ are various constants and exponents. $f_{r 1}, f_{r 2}$ and $f_{s}$ are the feed rate for the first rough pass, second rough pass and finish pass, respectively, $d_{r 1}, d_{r 2}$ and $d_{s}$ are the depth of cut for the first rough pass, second rough pass and finish pass, respectively, and $F_{\max }$ is the maximum allowable cutting force.

(c) Available machine tool power constraints:

$$
\begin{aligned}
& g_{4}(X)=\frac{C_{\lambda} K_{\lambda} W^{s_{\lambda}} Z^{p_{\lambda}} f_{r 1}^{y_{\lambda}} d_{r 1}^{x_{\lambda}} V_{r 1}}{D^{q_{\lambda}}}-P_{\max } \leq 0 \\
& g_{5}(X)=\frac{C_{\lambda} K_{\lambda} W^{s_{\lambda}} Z^{p_{\lambda}} f_{r 2}^{y_{\lambda}} d_{r 2}^{x_{\lambda}} V_{r 2}}{D^{q_{\lambda}}}-P_{\max } \leq 0 \\
& g_{6}(X)=\frac{C_{\lambda} K_{\lambda} W^{s_{\lambda}} Z^{p_{\lambda}} f_{s}^{y_{\lambda}} d_{s}^{x_{\lambda}} V_{s}}{D^{q_{\lambda}}}-P_{\max } \leq 0
\end{aligned}
$$

where $C_{\lambda}, K_{\lambda}, x_{\lambda}, y_{\lambda}, s_{\lambda}, p_{\lambda}$ and $q_{\lambda}$ are various constants and exponents, $V_{r 1}, V_{r 2}$ and $V_{s}$ are the cutting speed for the first rough pass, second rough pass and finish pass, respectively, and $P_{\max }$ is the maximum allowable machining power.

(d) Constraints for surface finish:

$$
\begin{aligned}
& g_{7}(X)=0.0321 \frac{f_{r 1}^{2}}{r_{e}}-R_{r \max } \leq 0 \\
& g_{8}(X)=0.0321 \frac{f_{r 2}^{2}}{r_{e}}-R_{r \max } \leq 0 \\
& g_{9}(X)=0.0321 \frac{f_{s}^{2}}{r_{e}}-R_{s \max } \leq 0
\end{aligned}
$$

where $r_{e}$ is the nose radius of the tool edge, and $R_{r \text { max }}$ and $R_{s \text { max }}$ are the required surface roughness values for rough passes and finish pass, respectively. 
(e) Tool life constraint:

$$
\begin{aligned}
& g_{10}(X)=\left(\frac{C_{v} K_{v} D^{q_{v}}}{V_{r 1} d_{r 1}^{x_{v}} f_{r 1}^{y_{v}} W^{s_{v}} Z^{p_{v}}}\right)^{\frac{1}{l}}-T_{R} \geq 0 \\
& g_{11}(X)=\left(\frac{C_{v} K_{v} D^{q_{v}}}{V_{r 2} d_{r 2}^{x_{v}} f_{r 2}^{y_{v}} W^{s_{v}} Z^{p_{v}}}\right)^{\frac{1}{l}}-T_{R} \geq 0 \\
& g_{12}(X)=\left(\frac{C_{v} K_{v} D^{q_{v}}}{V_{s} d_{s}^{x_{v}} f_{s}^{y_{v}} W^{s_{v}} Z^{p_{v}}}\right)^{\frac{1}{l}}-T_{R} \geq 0
\end{aligned}
$$

where $T_{R}$ is the tool replacement life (in $\min$ ) as specified by the machinist.

(f) Constraint for number of rough passes:

The total depth of cut $\left(d_{t}\right)$ for multi-pass milling operation is estimated as the sum of $n$ number of rough passes depth of cut and one finish pass depth of cut.

$$
d_{t}=\sum_{i=1}^{n} d_{r i}+d_{s}
$$

While optimizing different machining parameters for a multi-pass milling operation, the optimal number of passes needs to be determined. Based on the maximum depth of cut allowed in the roughing operation and depth of cut for a finish pass, the smallest number of rough passes $\left(n_{\min }\right)$ can be obtained as:

$$
n_{\min }=\operatorname{GInt}\left(\frac{d_{t}-d_{s \max }}{d_{r \max }}\right)
$$

where $d_{t}$ is the amount of total material to be removed, $d_{r \text { max }}$ is the maximum allowable depth of cut for rough passes, $d_{s \text { max }}$ is the maximum allowable depth of cut for finish pass and $\operatorname{GInt}(\cdot)$ is the greatest integer operator.

Based on the minimum depth of cut allowed in the roughing operation and depth of cut for a finish pass, the largest number of rough passes $\left(n_{\max }\right)$ can be derived as:

$$
n_{\max }=\operatorname{SInt}\left(\frac{d_{t}-d_{s \min }}{d_{r \min }}\right)
$$

where $d_{r \text { min }}$ is the minimum allowable depth of cut for rough passes, $d_{s \text { min }}$ is the minimum allowable depth of cut for finish pass and $\operatorname{SInt}(\cdot)$ is the smallest integer operator.

Hence, the number of rough milling passes $(n)$ required for machining the given part geometry can be estimated while considering a specific integer number between $n_{\min }$ and $n_{\text {max }}$.

Thus, the first objective function is formulated as:

$$
F_{1}(X)=\min (T)=\min \left(\sum_{i=1}^{n} T_{r i}+T_{s}+T_{p}\right)
$$


The second objective function is given by:

$$
F_{2}(X)=\min (C)=\min \left(\sum_{i=1}^{n} C_{r i}+C_{s}+k_{0} T_{p}\right)
$$

The objective function for simultaneous optimization of production time and production cost (multi-objective optimization) is developed as below:

$$
F_{3}(X)=\min (z)=w_{1} \frac{F_{1}(X)}{F_{1}(X)_{\min }}+w_{2} \frac{F_{2}(X)}{F_{2}(X)_{\min }}
$$

where $F_{1}(X)_{\min }$ and $F_{2}(X)_{\min }$ are the minimum values of production time and production cost, respectively achieved during single objective optimization, and $w_{1}$ and $w_{2}$ are the weights (relative importance) assigned to production time and production cost, respectively.

\section{METAHEURISTIC ALGORITHMS}

Metaheuristic-based optimization is a competent method for solving hard optimization problems in order to provide acceptable solutions in a reasonable time. The suffix 'meta' in metaheuristic refers to upper level methodology, and the word 'heuristic' denotes a new approach to solving problems which helps in guiding design of underlying mathematical approaches to solve specific optimization problems [18]. These optimization methods utilize algorithms which are simple, flexible and well accepted for fast solving of large scale problems. They can be applied to any problem that can be formulated as function optimization problems and can be effectively hybridized with other optimization techniques. Their major drawbacks are that most of them require fine-tuning of some algorithm specific parameters so as to obtain global optimal solutions; besides, they do not guarantee in repeatability of the optimal results with the same set of initial conditions [19]. However, their ability to solve large scale optimization problems easily and efficiently makes them a popular choice among the researchers for solving complex optimization problems. The two main components of metaheuristic algorithms are intensification and diversification [20]. Intensification refers to focusing on the search process in a local region while exploiting the information that a current good solution has been found out in this region, while diversification signifies the process of producing distinct solutions so as to explore the search space on a global scale. A suitable balance needs to be maintained between these two components which is crucial to preserve the overall efficiency and performance of the algorithm; otherwise, it may cause the system to be trapped in local optima and increase difficulty in convergence [21]. These algorithms usually employ mechanisms inspired from social behavior, nature, physical laws, etc. to achieve near global solutions in the search space through efficient and comprehensive exploration. They can be classified into two broad categories based on the number of solutions used at the same time, i.e. single solution- and population-based metaheuristic algorithms. In single solution-based algorithms, only one single solution is considered at a time, whereas, population-based algorithms work with a population of solutions to create new solutions. Greedy randomized adaptive search process (GRASP), SA, Tabu search (TS), etc. are some of the single solution-based algorithms. On the other hand, ACO, evolutionary algorithms, like GA, DE, etc. are few examples of population-based 
metaheuristics. The metaheuristic algorithms are also categorized into four major groups based on their origin, e.g. bio-inspired, swarm intelligence-based, physics/chemistry-based and others [22]. GA and DE are examples of the bio-inspired algorithms as they imitate the biological system of nature. Swarm intelligence-based algorithms mimic the collective behavior of a group of animals, like a flock of bird or fish, and insects, like bees, ants, wasps and termites. The most popular swarm intelligence-based algorithm is PSO technique which is also based on swarm behavior, like bird flocking and fish schooling. A cuckoo search algorithm is inspired by the process of breeding behavior of some species of cuckoo birds that lay eggs in the nests of host birds. The FA technique is another swarm intelligence-based algorithm that employs flashing behavior of swarming fireflies. The ACO technique is based on the behavior of ants searching a path between the source of food and their colony. Echolocation phenomenon of foraging bats is used by bat algorithm and foraging behavior of honey bees is employed in $\mathrm{ABC}$ algorithm. Thus, the phenomenon of ethology is employed in swarm intelligence-based algorithms [23]. Physics and chemistry-based metaheuristic algorithms are developed based on certain physical or chemical phenomena as observed in the universe. The SA, gravitational search algorithm and curved spaced optimization are some of the examples of physics-based optimization techniques. There are also certain metaheuristic algorithms inspired by human behaviors, like TLBO, imperialistic competitive algorithm, TS, firework algorithm etc.

In this paper, six metaheuristic algorithms, in the form of ABC, ACO, PSO, FA, DE and TLBO, are applied to solve the multi-objective mathematical model for a multi-pass face milling operation in order to determine the optimal values of cutting speed, feed rate and depth of cut for roughing and finishing operations. To achieve their best performance, the values of different algorithm-specific parameters are appropriately chosen, as provided in Table 1. All these algorithms are coded in Matlab 2013a, and run in 4.00 GB RAM 2.9 GHz processor and 32-bit operating platform. These six algorithms are simple and easy to implement with high computational efficiency. They have already been extensively applied to solve many engineering optimization problems due to their exceptional ability to search near optimal or global optimal solutions.

Table 1 Tuning parameters for six metaheuristic algorithms

\begin{tabular}{|c|c|}
\hline Metaheuristic & Parameter \\
\hline $\mathrm{ABC}$ algorithm & $\begin{array}{l}\text { Number of iterations }=300, \text { swarm size }=200, \text { number of employed bees }= \\
50 \% \text { of the swarm size, number of onlooker bees }=50 \% \text { of the swarm size, } \\
\text { number of scouts per cycle }=1, \text { number of cycles }=1000 \text { and limit }=50 .\end{array}$ \\
\hline ACO algorithm & $\begin{array}{l}\text { Number of iterations }=300, \text { sample size }=40 \text {, intensification factor }=0.5 \text { and } \\
\text { deviation distance ratio }=1 .\end{array}$ \\
\hline PSO algorithm & $\begin{array}{l}\text { Number of iterations }=300, \text { population size }=200 \text {, inertia weight factor }= \\
0.65, \text { and acceleration coefficients }=1.65 \text { and } 1.75 \text {. }\end{array}$ \\
\hline FA & $\begin{array}{l}\text { Number of iterations }=300, \text { number of fireflies }=200, \text { light absorption } \\
\text { coefficient }=1 \text {, initial randomness }=0.9, \text { randomness factor }=0.91 \text { and } \\
\text { randomness reduction }=0.75\end{array}$ \\
\hline DE algorithm & $\begin{array}{l}\text { Number of iterations }=300, \text { population size }=200 \text {, lower bound of scaling } \\
\text { factor }=0.5, \text { upper bound of scaling factor }=0.8, \text { crossover probability }=0.9 .\end{array}$ \\
\hline TLBO algorithm & Number of iterations $=300$ and population size $=200$. \\
\hline
\end{tabular}




\section{Metaheuristics-Based Optimization of A Multi-PASS Milling Process}

As already mentioned, this paper deals with the application of six metaheuristic algorithms, i.e. ABC, ACO, PSO, FA, DE and TLBO techniques for parametric optimization of a multipass face milling operation. Based on these algorithms, the optimal values of cutting speed, feed rate and depth of cut are determined with the aim to minimize total production time and total production cost separately. A multi-objective optimization model is also developed and subsequently solved using those algorithms while simultaneously minimizing both the objectives. Thus, Eqs. (43)-(45) are optimized subject to various practical machining constraints. The values of different machining data, constants and exponents, as used in the constraints, are provided in Table 2. Based on Eqs. (41)-(42) and taking the value of total depth of cut $\left(d_{t}\right)$ as $8 \mathrm{~mm}$, it is found that for the given part configuration, two rough passes are required, followed by one finish pass.

Table 2 Values of various machining data [9]

\begin{tabular}{|c|c|c|}
\hline & Symbol and unit & Numerical data \\
\hline \multicolumn{3}{|c|}{ Workpiece (Grey cast iron $190 \mathrm{HB}$ ) } \\
\hline Length & $L(\mathrm{~mm})$ & 230 \\
\hline Width & $W(\mathrm{~mm})$ & 90 \\
\hline \multicolumn{3}{|c|}{ Face-milling cutter (Cemented carbide) } \\
\hline Diameter & $D(\mathrm{~mm})$ & 160 \\
\hline Number of teeth & Z & 16 \\
\hline Nose radius of the cutting edge & $r_{e}(\mathrm{~mm})$ & 1 \\
\hline \multicolumn{3}{|c|}{ Milling cost and constraints } \\
\hline Overhead cost & $k_{0}(\mathrm{USD} / \mathrm{min})$ & 0.5 \\
\hline Cost of tool material & $k_{t}$ (USD/edge) & 2.5 \\
\hline Tool changing time & $T_{t c}(\min /$ edge $)$ & 1.5 \\
\hline Preparation time & $T_{p}(\min /$ edge $)$ & 0.75 \\
\hline Tool travel time & $h_{1}(\mathrm{~min} / \mathrm{mm})$ & 0.00007 \\
\hline Tool advance/depart time & $h_{2}(\min )$ & 0.3 \\
\hline Depth of cut (roughing) & {$\left[d_{r \min }, d_{r \max }\right](\mathrm{mm})$} & {$[2.0,4.0]$} \\
\hline Depth of cut (finishing) & {$\left[d_{\mathrm{s} \min }, d_{\mathrm{s} \max }\right](\mathrm{mm})$} & {$[0.5,2.0]$} \\
\hline Feed rate & {$\left[f_{\min }, f_{\max }\right](\mathrm{mm} /$ tooth $)$} & {$[0.1,0.6]$} \\
\hline Cutting speed & {$\left[v_{\min }, v_{\max }\right](\mathrm{m} / \min )$} & {$[50,300]$} \\
\hline Tool replacement life & $T_{R}(\min )$ & 240 \\
\hline Surface mean roughness & $R_{r \max }(\mu \mathrm{m})$ and $R_{s \max }(\mu \mathrm{m})$ & 25.0 and 2.5 \\
\hline Force & $F_{\max }(\mathrm{N})$ & 8000 \\
\hline Power & $P_{\max }(\mathrm{kW})$ & 8 \\
\hline \multicolumn{3}{|c|}{ Constants and exponents in face milling } \\
\hline \multicolumn{3}{|c|}{ Equation $\quad$ Constants/exponents } \\
\hline \multicolumn{3}{|c|}{ Tool life: $C_{v}=445, K_{v}=1.0, x_{v}=0.15, y_{v}=0.35, p_{v}=0, q_{v}=0.2, s_{v}=0.2, l=0.32$} \\
\hline \multicolumn{3}{|c|}{ Force: $\quad C_{u}=534.6, K_{u}=1, x_{u}=0.9, y_{u}=0.74, p_{u}=1, q_{u}=1.0, s_{u}=1.0$} \\
\hline \multicolumn{3}{|c|}{$C_{\lambda}=0.5346, K_{\lambda}=1, x_{\lambda}=0.9, y_{\lambda}=0.74, p_{\lambda}=0, q_{\lambda}=1, \mathrm{~s}_{\lambda}=1.0$} \\
\hline
\end{tabular}


The results of solving the single objective optimization problems for minimum total production time and total production cost using the six adopted metaheuristic algorithms are exhibited in Tables 3 and 4, respectively. It is interestingly observed that these algorithms successfully satisfy all the considered practical constraints, and TLBO algorithm supersedes the others with respect to both the minimum total production time and total production cost. For this algorithm, the minimum total production time is derived as $0.9805 \mathrm{~min}$ and the minimum total production cost is obtained as 1.44875 USD for the given part geometry. Tables 3 and 4 also provide the optimal values of cutting speed, feed rate and depth of cut for both the roughing and finishing operations for all the considered algorithms. In Fig. 2, the convergence diagrams for total production time and total production cost as the objective functions are shown. It can be clearly revealed from this figure that the TLBO algorithm reaches the minimum values for both these objectives quite quickly as compared to others. Actually, this algorithm takes only 5-10 iterations to arrive at the minimal values. Amongst the six algorithms, the optimization performance of FA technique is observed to be the worst.

Table 3 Results for minimum total production time

\begin{tabular}{|c|c|c|c|c|c|c|c|c|c|}
\hline & Variable & Unit & $\begin{array}{c}\text { Range/ } \\
\text { limit }\end{array}$ & $\mathrm{ABC}$ & $\mathrm{ACO}$ & PSO & FA & $\mathrm{DE}$ & TLBO \\
\hline \multirow{9}{*}{$\begin{array}{l}\text { Cutting } \\
\text { parameters }\end{array}$} & $V_{r 1}$ & $\mathrm{~m} / \mathrm{min}$ & $50-300$ & 85.3967 & 85.2367 & 85 & 85.3349 & 85.3843 & 85.4 \\
\hline & $V_{r 2}$ & $\mathrm{~m} / \mathrm{min}$ & $50-300$ & 65.4576 & 65.4147 & 65.5 & 65.2577 & 65.4663 & 65.5 \\
\hline & $V_{s}$ & $\mathrm{~m} / \mathrm{min}$ & $50-300$ & 137.0874 & 137.0199 & 137 & 137.0848 & 137.0015 & 137.1 \\
\hline & $f_{r 1}$ & $\mathrm{~mm} /$ tooth & $0.1-0.6$ & 0.6020 & 0.6020 & 0.6 & 0.6082 & 0.6001 & 0.6 \\
\hline & $f_{r 2}$ & $\mathrm{~mm} /$ tooth & $0.1-0.6$ & 0.6001 & 0.5999 & 0.6 & 0.6013 & 0.6032 & 0.6 \\
\hline & $f_{s}$ & $\mathrm{~mm} /$ tooth & $0.1-0.6$ & 0.2514 & 0.2552 & 0.2550 & 0.2560 & 0.255 & 0.252 \\
\hline & $d_{r 1}$ & $\mathrm{~mm}$ & $2-4$ & 2.2731 & 2.2726 & 2.2811 & 2.2823 & 2.2957 & 2.27 \\
\hline & $d_{r 2}$ & $\mathrm{~mm}$ & $2-4$ & 2.3173 & 2.3424 & 2.3 & 2.347 & 2.3359 & 2.3 \\
\hline & $d_{s}$ & $\mathrm{~mm}$ & $0.5-2$ & 0.593 & 0.5928 & 0.5920 & 0.593 & 0.593 & 0.592 \\
\hline \multirow{12}{*}{ Constraints } & $g_{1}(X)$ & & $\leq 0$ & -1079.9 & -1081 & -1105.12 & -1001.56 & -1034.05 & -1105.12 \\
\hline & $g_{2}(X)$ & & $\leq 0$ & -975.905 & -908.391 & -1023.17 & -883.594 & -897.329 & -1023.17 \\
\hline & $g_{3}(X)$ & & $\leq 0$ & -6908.06 & -6906.09 & -6908.06 & -6903.22 & -6906.4 & -6908.06 \\
\hline & $g_{4}(X)$ & & $\leq 0$ & -7963.07 & -7963.14 & -7963.37 & -7962.67 & -7962.83 & -7963.2 \\
\hline & $g_{5}(X)$ & & $\leq 0$ & -7971.26 & -7971.01 & -7971.44 & -7970.97 & -7970.94 & -7971.44 \\
\hline & $g_{6}(X)$ & & $\leq 0$ & -7850.31 & -7850.11 & -7850.29 & -7849.65 & -7850.17 & -7850.4 \\
\hline & $g_{7}(X)$ & & $\leq 0$ & -0.02355 & -0.02355 & -0.02352 & -0.02355 & -0.02355 & -0.02355 \\
\hline & $g_{8}(X)$ & & $\leq 0$ & -0.00427 & -0.00428 & -0.00432 & -0.00441 & -0.00485 & -0.00432 \\
\hline & $g_{9}(X)$ & & $\leq 0$ & -0.02474 & -0.02474 & -0.02474 & -0.02474 & -0.02474 & -0.02474 \\
\hline & $g_{10}(X)$ & & $\geq 0$ & 55.503 & 57.191 & 61.04 & 52.239 & 55.21 & 56.655 \\
\hline & $g_{11}(X)$ & & $\geq 0$ & 434.4418 & 432.6057 & 435.5096 & 435.3286 & 427.8060 & 435.5096 \\
\hline & $g_{12}(X)$ & & $\geq 0$ & 83.6276 & 83.6108 & 83.5022 & 81.9771 & 83.9732 & 84.2407 \\
\hline $\begin{array}{l}\text { Production } \\
\text { time }\end{array}$ & & $\min$ & & 0.9809 & 0.9811 & 0.9808 & 0.9826 & 0.9812 & 0.9805 \\
\hline
\end{tabular}


Table 4 Results for minimum total production cost

\begin{tabular}{|c|c|c|c|c|c|c|c|c|c|}
\hline & Variable & Unit & $\begin{array}{l}\text { Range } \\
\text { /limit }\end{array}$ & $\mathrm{ABC}$ & $\mathrm{ACO}$ & PSO & FA & $\mathrm{DE}$ & TLBO \\
\hline \multirow{9}{*}{$\begin{array}{l}\text { Cutting } \\
\text { parameters }\end{array}$} & $V_{r 1}$ & $\mathrm{~m} / \mathrm{min}$ & $50-300$ & 85.3765 & 85.2473 & 85.3497 & 85.3545 & 85.3946 & 85 \\
\hline & $V_{r 2}$ & $\mathrm{~m} / \mathrm{min}$ & $50-300$ & 65.1546 & 65.016 & 65.2144 & 65.2265 & 65.2465 & 65.5 \\
\hline & $V_{s}$ & $\mathrm{~m} / \mathrm{min}$ & $50-300$ & 137.0030 & 137.0905 & 137.0129 & 137.0197 & 137.0746 & 137 \\
\hline & $f_{r 1}$ & $\mathrm{~mm} /$ tooth & $0.1-0.6$ & 0.5998 & 0.5998 & 0.5941 & 0.612 & 0.6 & 0.6 \\
\hline & $f_{r 2}$ & $\mathrm{~mm} /$ tooth & $0.1-0.6$ & 0.6 & 0.6003 & 0.6030 & 0.6005 & 0.6 & 0.6 \\
\hline & $f_{s}$ & $\mathrm{~mm} /$ tooth & $0.1-0.6$ & 0.2553 & 0.2550 & 0.2553 & 0.2554 & 0.2554 & 0.2555 \\
\hline & $d_{r 1}$ & $\mathrm{~mm}$ & $2-4$ & 2.2956 & 2.2922 & 2.296 & 2.285 & 2.2714 & 2.2712 \\
\hline & $d_{r 2}$ & $\mathrm{~mm}$ & $2-4$ & 2.3191 & 2.3440 & 2.3591 & 2.3459 & 2.3004 & 2.3 \\
\hline & $d_{s}$ & $\mathrm{~mm}$ & $0.5-2$ & 0.5928 & 0.5928 & 0.5929 & 0.5925 & 0.593 & 0.592 \\
\hline \multirow{12}{*}{ Constraints } & $g_{1}(X)$ & & $\leq 0$ & -1043.77 & -1038.46 & -1038.38 & -1053.87 & -1105.12 & -1105.12 \\
\hline & $g_{2}(X)$ & & $\leq 0$ & & -900.531 & -835.63 & -893.6 & -1022.07 & -1023.17 \\
\hline & $g_{3}(X)$ & & $\leq 0$ & -6906.73 & -6906.73 & -6905.61 & -6905.96 & -6906.4 & -6906.4 \\
\hline & $g_{4}(X)$ & & $\leq 0$ & -7962.88 & -7962.91 & -7962.86 & -7962.95 & -7963.2 & -7963.27 \\
\hline & $g_{5}(X)$ & & $\leq 0$ & -7971.38 & -7971.15 & -7970.8 & -7971.03 & -7971.54 & -7971.44 \\
\hline & $g_{6}(X)$ & & $\leq 0$ & -7850.22 & -7850.12 & -7850.08 & -7850.09 & -7850.09 & -7850.4 \\
\hline & $g_{7}(X)$ & & $\leq 0$ & -0.02356 & -0.02355 & -0.02356 & -0.02356 & -0.02356 & -0.02356 \\
\hline & $g_{8}(X)$ & & $\leq 0$ & -0.00386 & -0.00392 & -0.00385 & -0.00405 & -0.00432 & -0.00432 \\
\hline & $g_{9}(X)$ & & $\leq 0$ & -0.02474 & -0.02474 & -0.02474 & -0.02474 & -0.02474 & -0.02474 \\
\hline & $g_{10}(X)$ & & $\geq 0$ & 55.8935 & 56.5830 & 55.8896 & 55.6956 & 56.7142 & 61.04004 \\
\hline & $g_{11}(X)$ & & $\geq 0$ & 444.4484 & 444.8605 & 433.6894 & 437.47 & 443.6846 & 435.5096 \\
\hline & $g_{12}(X)$ & & $\geq 0$ & 84.01337 & 83.3675 & 83.4983 & 83.4119 & 83.4336 & 84.2407 \\
\hline $\begin{array}{l}\text { roducti } \\
\text { ost }\end{array}$ & & USD & & 1.44892 & 1.44912 & 1.44916 & 1.44917 & 1.44882 & 1.44875 \\
\hline
\end{tabular}

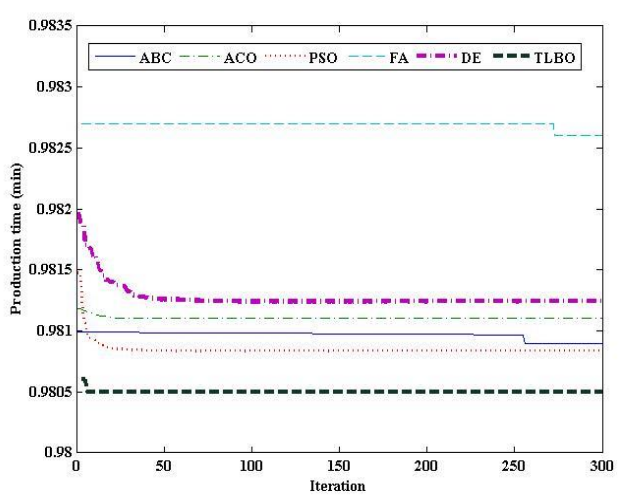

(a)

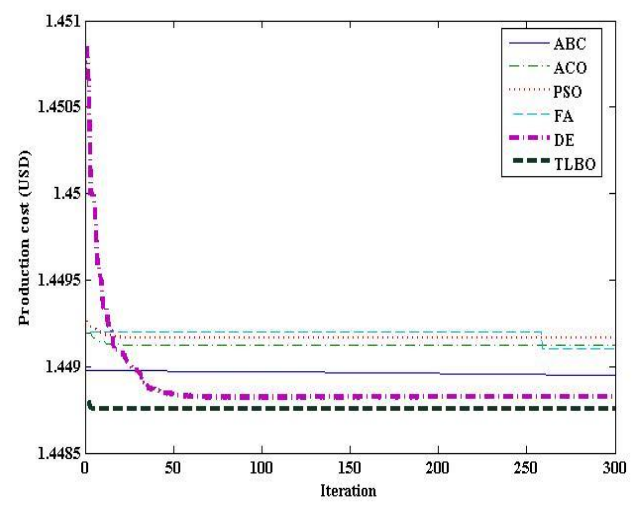

(b)

Fig. 2 Convergence diagrams for six metaheuristic algorithms

On the other hand, the boxplots exhibiting the variability in the values of total production time and total production cost for the six algorithms are depicted in Fig. 3. A higher length of the box represents more variability in the derived solutions. It can be 
noticed from this figure that the TLBO algorithm provides more consistent solutions for both the objective functions with low variability. The DE algorithm performs worst with quite high variability in the obtained solutions. Thus, it can be concluded that the performance of the TLBO algorithm is superior to the remaining optimization techniques with respect to accuracy and consistency of the derived solutions as well as convergence speed.

In order to validate the uniqueness of the TLBO algorithm, and identify the presence of any significant difference between the optimization performance of the considered metaheuristic algorithms, two statistical tests, i.e. paired $t$-test (parametric test) and the Wilcoxson signed rank test (non-parametric test) are now performed with the following hypotheses:

- $H_{0}$ (Null hypothesis): Population means for two algorithms are equal $\left(\mu_{1}=\mu_{2}\right)$.

- $H_{\alpha}$ (Alternate hypothesis): Population means for two algorithms are not equal $\left(\mu_{1} \neq \mu_{2}\right)$.

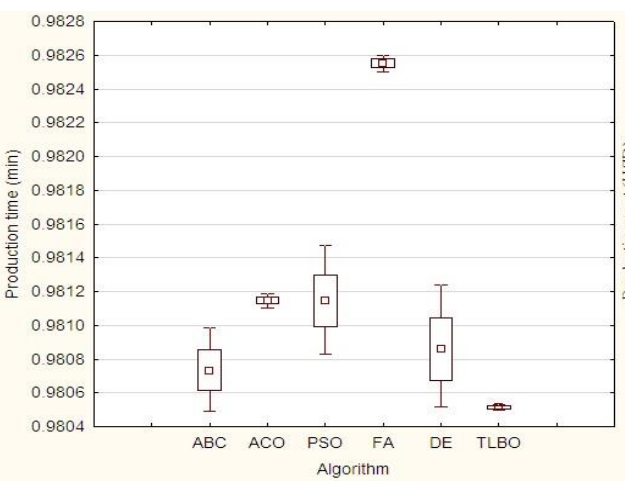

(a)

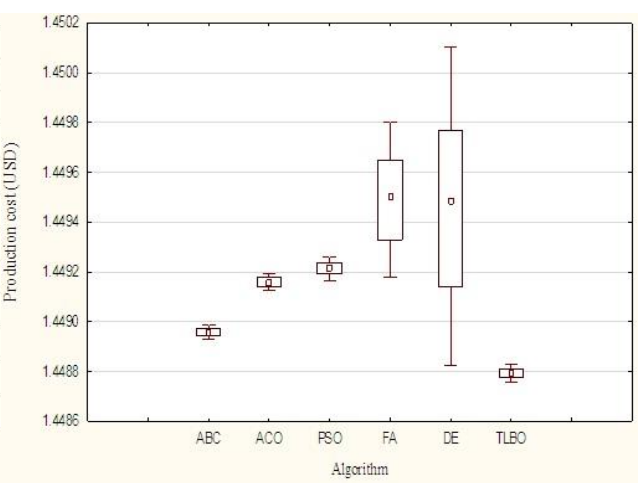

(b)

Fig. 3 Boxplots for the considered metaheuristic algorithms

In these hypotheses, the population mean signifies the average value of each of the objective functions calculated after 300 iterations for all the metaheuristics considered. The results of the paired $t$-test for total production time and total production cost are shown in Tables 5 and 6, respectively. For both the objectives, as the absolute values of $t$ statistic for the paired comparisons between the TLBO and other algorithms are higher than the corresponding critical values of $t$ at $5 \%$ level of significance, the null hypotheses for all the paired $t$-tests can thereby be rejected. Similarly, Tables 7 and 8 , respectively, show the results of the Wilcoxson signed rank test with the calculated $p$-values for all the pair-wise comparisons between the TLBO and remaining algorithms for both the objectives. The $p$-values are observed to be less than 0.05 at $5 \%$ level of significance for all the paired comparisons. The results of these statistical tests thus again prove the uniqueness and best optimization performance of the TLBO algorithm against the other metaheuristic algorithms. 
Table 5 Results of paired $t$-test for total production time

\begin{tabular}{ccccc}
\hline ABC & ACO & PSO & FA & DE \\
\hline-851.188 & -1608.38 & -155.843 & -206.373 & -869.86 \\
\hline
\end{tabular}

Table 6 Results of paired $t$-test for total for production cost

\begin{tabular}{ccccc}
\hline ABC & ACO & PSO & FA & DE \\
\hline-293.9 & -1103.97 & -1012.78 & -12.83 & -1383.58 \\
\hline
\end{tabular}

Table 7 Results of the Wilcoxson signed rank test for total production time

\begin{tabular}{ccccc}
\hline $\mathrm{ABC}$ & $\mathrm{ACO}$ & PSO & FA & DE \\
\hline 0.0002 & 0.0001 & 0.0007 & 0.0008 & 0.0003 \\
\hline
\end{tabular}

Table 8 Results of the Wilcoxson signed rank test for total production cost

\begin{tabular}{ccccc}
\hline $\mathrm{ABC}$ & $\mathrm{ACO}$ & PSO & FA & DE \\
\hline 0.0014 & 0.0018 & 0.0024 & 0.0028 & 0.0037 \\
\hline
\end{tabular}

For multi-objective optimization of both the total production time and total production cost, the objective function of Eq. (45) is now optimized using all the six metaheuristics. In this case, equal importance (weight) is provided to both the objectives. Table 9 exhibits the results of this multi-objective optimization which again proves the excellent performance of the TLBO algorithm as compared to others. The minimum value of objective function $(z)$ is observed to be 1.00007 with the total production time as $0.9552 \mathrm{~min}$ and total production cost as 1.4220 USD while satisfying all the given machining constraints. The optimal values of cutting speed, feed rate and depth of cut for roughing and finishing operations for the considered multi-pass face milling operation would thus simultaneously minimize both the total production time and total production cost. The corresponding convergence diagram and boxplots, as shown in Fig. 4, also signify the best optimization performance of the TLBO algorithm. The results of paired $t$-test and Wilcoxson signed rank test, as provided in Tables 10 and 11, respectively, prove that the optimization performance of the TLBO algorithm is unique and best among all the considered metaheuristic algorithms. Thus, it can be applied as an almost global optimization tool for parametric optimization of a multi-pass milling process.

As already mentioned, this paper deals with comparing the optimization performance of six well known metaheuristic algorithms in order to determine minimum total production cost and total production time in a multi-pass face milling operation. Each algorithm has its unique characteristics, and before its execution, its different parameters must be properly tuned; otherwise, it may lead to local optimal solution. These parameters are considered to be the vital elements in any algorithm. Due to stochastic behavior of these algorithms, each algorithm generates different results in each run. Therefore, in this paper, the best solution is determined after performing 30 independent runs for each algorithm. The best solution determined by each algorithm is recorded and subsequently compared. The process of performing independent runs for each algorithm thus reduces randomness in the derived results. 
Table 9 Results of multi-objective optimization for multi-pass milling process

\begin{tabular}{|c|c|c|c|c|c|c|c|c|c|}
\hline & Variable & Unit & $\begin{array}{c}\text { Range/ } \\
\text { limit }\end{array}$ & $\mathrm{ABC}$ & $\mathrm{ACO}$ & PSO & FA & $\mathrm{DE}$ & TLBO \\
\hline \multirow{9}{*}{$\begin{array}{l}\text { Cutting } \\
\text { parameters }\end{array}$} & $V_{r 1}$ & $\mathrm{~m} / \mathrm{min}$ & $50-300$ & 85.38 & 85.2145 & 85 & 85.1619 & 85.3947 & 85.4 \\
\hline & $V_{r 2}$ & $\mathrm{~m} / \mathrm{min}$ & $50-300$ & 65.3296 & 65.4622 & 65.5 & 65.2529 & 65.4988 & 64 \\
\hline & $V_{s}$ & $\mathrm{~m} / \mathrm{min}$ & $50-300$ & 137.0614 & 137.0311 & 137.1 & 137.0862 & 137.0993 & 137 \\
\hline & $f r_{1}$ & $\mathrm{~mm} /$ tooth & $0.1-0.6$ & 0.5988 & 0.6 & 0.6 & 0.6 & 0.512 & 0.411 \\
\hline & $f r_{2}$ & $\mathrm{~mm} /$ tooth & $0.1-0.6$ & 0.6 & 0.6 & 0.6 & 0.6 & 0.6 & 0.6 \\
\hline & $f_{s}$ & $\mathrm{~mm} /$ tooth & $0.1-0.6$ & 0.2557 & 0.2554 & 0.255 & 0.256 & 0.255 & 0.255 \\
\hline & $d r_{1}$ & $\mathrm{~mm}$ & $2-4$ & 2.2838 & 2.2903 & 2.27 & 2.2925 & 2.271 & 2.227 \\
\hline & $d r_{2}$ & $\mathrm{~mm}$ & $2-4$ & 2.3698 & 2.3773 & 2.3 & 2.35 & 2.38 & 2.3 \\
\hline & $d_{s}$ & $\mathrm{~mm}$ & $0.5-2$ & 0.5926 & 0.5921 & 0.592 & 0.5929 & 0.5924 & 0.501 \\
\hline \multirow{12}{*}{ Constraints } & $g_{1}(X)$ & & $\leq 0$ & -1069.12 & -1049.65 & -1105.12 & -1143.64 & -1868.67 & -2877.73 \\
\hline & $g_{2}(X)$ & & $\leq 0$ & -832.893 & -812.481 & -1023.17 & -886.809 & -805.135 & -1023.17 \\
\hline & $g_{3}(X)$ & & $\leq 0$ & -6904.84 & -6906.62 & -6908.06 & -6903.39 & -6907.39 & -7060.35 \\
\hline & $g_{4}(X)$ & & $\leq 0$ & -7963.02 & -7962.98 & -7963.37 & -7962.97 & -7967.28 & -7972.66 \\
\hline & $\mathrm{g}_{5}(X)$ & & $\leq 0$ & -7970.74 & 7970.59 & -7971.44 & -7970.97 & -7970.55 & -7972.09 \\
\hline & $g_{6}(X)$ & & $\leq 0$ & -7849.9 & -7850.17 & -7850.29 & -7849.67 & -7850.2 & -7871.27 \\
\hline & $g_{7}(X)$ & & $\leq 0$ & -0.02356 & -0.02356 & -0.02356 & -0.02356 & -0.02395 & -0.02432 \\
\hline & $g_{8}(X)$ & & $\leq 0$ & -0.00407 & -0.02356 & -0.00432 & -0.00393 & -0.00432 & -0.0051 \\
\hline & $g_{9}(X)$ & & $\leq 0$ & -0.02474 & -0.02474 & -0.02474 & -0.00247 & -0.02474 & -0.02474 \\
\hline & $g_{10}(X)$ & & $\geq 0$ & 56.13855 & 57.43446 & 61.04004 & 57.8748 & 112.9195 & 212.7508 \\
\hline & $g_{11}(X)$ & & $\geq 0$ & 431.5535 & 426.3241 & 435.5096 & 435.3978 & 424.8074 & 486.2283 \\
\hline & $g_{12}(X)$ & & $\geq 0$ & 82.6644 & 83.5022 & 83.5022 & 81.9923 & 83.4049 & 110.6262 \\
\hline $\begin{array}{l}\text { Production } \\
\text { time }\end{array}$ & & $\min$ & & 0.98090 & 0.98083 & 0.9808 & 0.9812 & 0.9677 & 0.9552 \\
\hline $\begin{array}{l}\text { Production } \\
\text { cost }\end{array}$ & & USD & & 1.44892 & 1.44894 & 1.4487 & 1.4489 & 1.4349 & 1.4220 \\
\hline$z$ & & & & 1.00033 & 1.00036 & 1.000241 & 1.00154 & 1.00019 & 1.00007 \\
\hline
\end{tabular}

Table 10 Results of paired $t$-test for multi-objective optimization

\begin{tabular}{ccccc}
\hline $\mathrm{ABC}$ & $\mathrm{ACO}$ & $\mathrm{PSO}$ & $\mathrm{FA}$ & $\mathrm{DE}$ \\
\hline-87.580 & -78.704 & -88.073 & -618.248 & -22.8169 \\
\hline
\end{tabular}

Table 11 Results of Wilcoxson signed rank test for multi-objective optimization

\begin{tabular}{ccccc}
\hline ABC & ACO & PSO & FA & DE \\
\hline 0.0024 & 0.0021 & 0.0032 & 0.0031 & 0.0011 \\
\hline
\end{tabular}




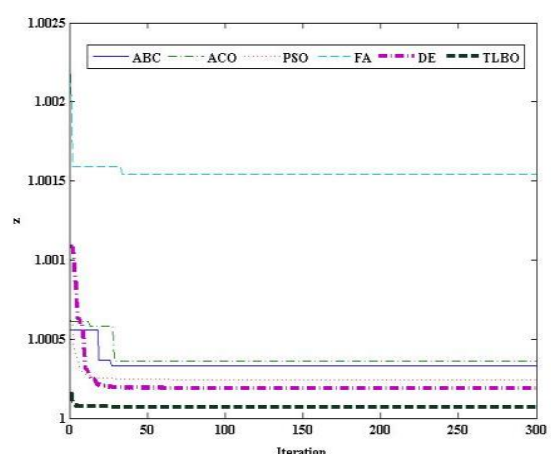

(a)

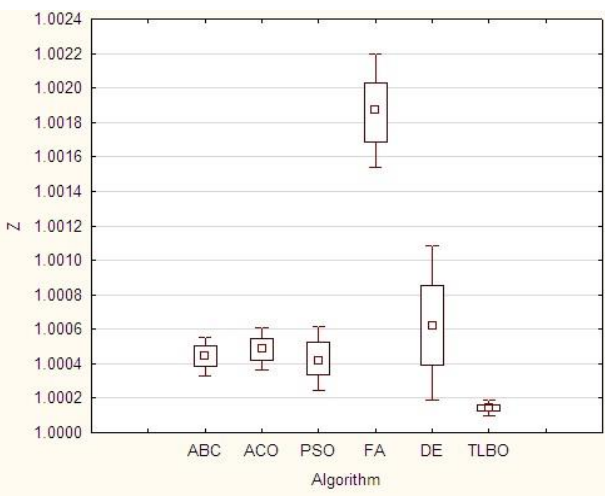

(b)

Fig. 4 Convergence diagram and boxplots for multi-objective optimization

\section{CONCLUSIONS}

In this paper, an endeavor is put forward for parametric optimization of a multi-pass face milling operation using six most popular metaheuristic algorithms. These algorithms are employed to determine the optimal values of cutting speed, feed rate and depth of cut for both roughing and finishing operations of the considered milling process while minimizing total production time and total production cost. Based on the derived results, it can be revealed that the application of the TLBO algorithm estimates the minimum total production time and total production cost as $0.9805 \mathrm{~min}$ and $1.44875 \mathrm{USD}$, respectively, for the considered part geometry. As compared to the remaining algorithms, it converges quite quickly towards the almost global solution and the derived solutions are highly consistent with minimum variability. The applications of the paired $t$-test and the Wilcoxson signed rank test also confirm its superiority over the other algorithms. The results of multi-objective optimization of the considered multi-pass milling process using the TLBO algorithm show that the values of total production time as $0.9552 \mathrm{~min}$ and total production cost as 1.4220 USD are obtained while simultaneously minimizing both the objectives. Thus, it can be concluded that the TLBO algorithm can be employed as an effective tool for both single and multi-objective optimization of any of the machining processes.

\section{REFERENCES}

1. Shunmugam, M.S., Bhaskara Reddy, S.V., Narendran, T.T., 2000, Selection of optimal conditions in multipass face-milling using a genetic algorithm, International Journal of Machine Tools and Manufacture, 40(3), pp. 401-414.

2. Tolouei-Rad, M., Bidhendi, I.M., 1997, On the optimization of machining parameters for milling operations, International Journal of Machine Tools and Manufacture, 37(1), pp.1-16.

3. Shin, Y.C., Joo, Y.S., 1992, Optimization of machining conditions with practical constraints, International Journal of Production Research, 30(12), pp. 2907-2919.

4. Conceição António, C.A., Castro, C.F., Davim, J.P., 2009, Optimisation of multi-pass cutting parameters in face-milling based on genetic search, International Journal of Advanced Manufacturing Technology, 44(1112), pp.1106-1115. 
5. Zarei, O., Fesanghary, M., Farshi, B., Saffar, R.J., Razfar, M.R., 2009, Optimization of multi-pass facemilling via harmony search algorithm, Journal of Materials Processing Technology, 209(5), pp. 2386-2392.

6. Rao, R.V., Pawar, P.J., 2010, Parameter optimization of a multi-pass milling process using non-traditional optimization algorithms, Applied Soft Computing, 10(2), pp. 445-456.

7. An, L., Feng, L., Lu, C., 2011, Cutting parameter optimization for multi-pass milling operations by genetic algorithms, Advanced Materials Research, 160-162, pp. 1738-1743.

8. Yang, W-A., Guo, Y., Liao, W-H., 2011, Optimization of multi-pass face milling using a fuzzy particle swarm optimization algorithm, International Journal of Advanced Manufacturing Technology, 54(1-4), pp. 45-57.

9. Yang, W-A., Guo, Y., Liao, W., 2011, Multi-objective optimization of multi-pass face milling using particle swarm intelligence, International Journal of Advanced Manufacturing Technology 56(5-8), pp. 429-443.

10. An, L., Yang, P., Zhang, H., Chen, M., 2014, Multi-objective optimization for milling operations using genetic algorithms under various constraints, International Journal of Networked and Distributed Computing, 2(2), pp. 108-114.

11. Nagarchi, M.B., Patel, D.A., 2014, Parametric optimization of face milling using harmony search algorithm, International Journal of Engineering Development and Research, 2(2), pp. 1722-1729.

12. Zhai, Z., Li, S., Liu, Y., 2015, Parameter determination of milling process using a novel teaching-learningbased optimization algorithm, Mathematical Problems in Engineering, Article ID 425689, 14 pages.

13. Mellal, M.A., Williams, E.J., 2016, Total production time minimization of a multi-pass milling process via cuckoo optimization algorithm, International Journal of Advanced Manufacturing Technology, 87(1-4), pp. 747-754.

14. Li, C., Chen, X., Tang, Y., Li, L, 2017, Selection of optimum parameters in multi-pass face milling for maximum energy efficiency and minimum production cost, Journal of Cleaner Production, 140(3), pp. 1805-1818.

15. Khalilpourazari, S., Khalilpourazary, S., 2018, Optimization of production time in the multi-pass milling process via a robust grey wolf optimizer, Neural Computing and Applications, 29(12), pp. 1321-1336.

16. Yang, Y., 2018, Machining parameters optimization of multi-pass face milling using a chaotic imperialist competitive algorithm with an efficient constraint-handling mechanism, Computer Modeling in Engineering and Sciences, 116(3), pp. 365-389.

17. Miodragović, G.R., Đordević, V., Bulatović, R.R., Petrović, A., 2019, Optimization of multi-pass turning and multi-pass face milling using subpopulation firefly algorithm, Proceedings of IMechE Part C: Journal of Mechanical Engineering Science, 233(5), pp. 1520-1540.

18. Talbi, E.G., 2009, Metaheuristics: From Design to Implementation. John Wiley \& Sons, New Jersey, USA.

19. Madić, M., Marković, D., Radovanović, M., 2013, Comparison of meta-heuristic algorithms for solving machining optimization problems, Facta Universitatis-Series Mechanical Engineering, 11(1), pp. $29-44$.

20. Blum, C., Roli, A., 2003, Metaheuristics in combinatorial optimisation: Overview and conceptual comparison, ACM Computing Surveys, 35(3), pp. 268-308.

21. Yang, X.S., 2011, Review of metaheuristics and generalized evolutionary walk algorithm, International Journal of Bio-Inspired Computation, 3(2), pp. 77-84.

22. Gendreau, M., Potvin, J.Y., 2005, Metaheuristics in combinatorial optimization, Annals of Operations Research, 140(1), pp. 189-213

23. Fister, Jr.I., Yang, X.S., Fister, I., Brest, J., Fister, D., 2013, A brief review of nature-inspired algorithms for optimization, Elektrotehniski Vestnik, 80(3), pp.1-7. 